\title{
DAS RODAS DE CONVERSA AOS JOGOS EDUCATIVOS: TRABALHANDO A MATEMÁTICA A PARTIR DO LÚDICO
}

\author{
Danilo de Sousa Cezário, Universidade Federal de Campina Grande (UFCG) \\ danilomotos@hotmail.com \\ Erica Dantas da Silva, Universidade Federal de Campina Grande (UFCG) \\ ericadantasdasilva70@gmail.com \\ Paloma Ferreira Rolim, Universidade Federal de Campina Grande (UFCG) \\ palomarolim4@gmail.com
}

\begin{abstract}
RESUMO
O presente texto tem como objetivo elucidar aspectos concernentes à importância de incorporar a ludicidade no ensino da matemática, na educação infantil e nos anos iniciais do ensino fundamental. Tem-se, por exemplo, a importância de se inovar no âmbito educacional, por intermédio do uso de jogos educativos, haja vista que se faz necessário que essa mediação ocorra o quanto antes possível, uma vez que esta oportuniza um aprimoramento do raciocínio lógico, imaginação, criatividade, amplificação do pensamento e da linguagem e, consequentemente o desenvolvimento da socialização. Tem-se como aporte teórico os textos discutidos na disciplina Fundamentos e Metodologia do Ensino da Matemática do curso de pedagogia (CFP/UFCG), cujos autores são Canal, Cruz, Gostenski, Barbieri, Camargo, Reame, RCNs (1998), bem como a elaboração de jogos educativos desenvolvidos no âmbito acadêmico. Elucidar-se-á algumas das potencialidades que podem vir a ser desenvolvidas na criança com a combinação entre as atividades de aprendizagem e o brincar. Nessa perspectiva, pretende-se discutir novas metodologias através de jogos e brincadeiras para serem desenvolvidas durante as aulas de maneira a contribuir integralmente para o processo de ensino-aprendizagem.
\end{abstract}

PALAVRAS-CHAVE: Ludicidade; Práticas inovadoras; Ensino-aprendizagem. 


\title{
OF THE WHEELS OF CONVERSATION TO EDUCATIONAL GAMES: WORKING MATHEMATICS FROM THE LÚDICO
}

\begin{abstract}
This paper has as an objective to elucidate aspects concerning the importance of incorporating ludic activities in the teaching of Mathematics, in the early years of childhood education and in the initial years of elementary education. There is, for example, the importance of innovation in education, through the use of educational games, and it is necessary that this mediation occurs as soon as possible, since it facilitates the improvement of logical thinking, imagination, creativity, amplification of thoughts and language and, consequently, the development of socialization. As theoretical contribution, were used some of the texts discussed in the discipline Fundamentos e Metodologia do Ensino da Matemática from the Education Department (Pedagogia - CFP / UFCG), whose authors are Canal, Cruz, Gostenski, Barbieri, Camargo, Reame, RCNs (1998), as well as the elaboration of educational games developed at the university. It will be elucidated some potential skills that children can develop through the combination of learning activities and playing. In this perspective, we intend to discuss new methodologies through games and play to be done during classes in order to contribute to the process of teaching and learning.
\end{abstract}

KEYWORDS: Ludic language; Innovative practices; Teaching and learning

\section{DE LAS RUEDAS DE CONVERSACIÓN A LOS JUEGOS EDUCATIVOS: TRABAJANDO LA MATEMÁTICA A PARTIR DEL LÚDICO}

\section{RESUMEN}

El presente texto tiene como objetivo elucidar aspectos concernientes a la importancia de incorporar la ludicidad en la enseñanza de las matemáticas, en la educación infantil y en los años iniciales de la enseñanza fundamental. Se tiene, por ejemplo, la importancia de innovar en el ámbito educativo, por intermedio del uso de juegos educativos, hay que ver que se hace necesario que esa mediación ocurra lo antes posible, ya que esta oportuniza un perfeccionamiento del razonamiento lógico, Imaginación, creatividad, amplificación del pensamiento y del lenguaje y, consecuentemente, el desarrollo de la socialización. En el caso de la enseñanza de la matemática del curso de pedagogía (CFP / UFCG), cuyos autores son Canal, Cruz, Gostenski, Barbieri, Camargo, Reen, RCNs (1998), así como los temas discutidos en la disciplina Fundamentos y Metodología de la enseñanza de la matemática del curso de pedagogía (CFP / UFCG) La elaboración de juegos educativos desarrollados en el ámbito académico. Se eluden algunas de las potencialidades que pueden desarrollarse en el niño con la combinación entre las actividades de aprendizaje y el juego. En esta perspectiva, se pretende discutir nuevas metodologías a través de juegos y juegos para ser desarrolladas durante las clases de manera a contribuir integralmente al proceso de enseñanza-aprendizaje.

PALABRAS CLAVE: Ludicidad; Prácticas innovadoras; Enseñanza-aprendizaje. 


\section{INTRODUÇÃOO}

Ao se tratar da importância do ensino da matemática na educação infantil, considerase que esta oportuniza um desenvolvimento do raciocínio lógico como forma de aplicar essa habilidade nas situações advindas do cotidiano, tais como: compra e venda de produtos, cálculos de distância, pesos e medidas, como também orientação quanto as horas.

Levando em consideração os aspectos já mencionados, pode-se discutir a importância de aulas inovadoras no ensino da matemática, tanto na educação infantil, quanto nos anos iniciais do ensino fundamental, uma vez que para desenvolver tais atividades é possível fazer uso de diversas metodologias de ensino, a exemplo da realização de jogos educativos, músicas e objetos concretos existentes na sala. Além disso, pode-se também permitir que crianças atuem como sujeitos ativos das aulas, sendo essa uma forma delas desenvolverem sua autonomia, criatividade, imaginação e que de fato as crianças se sintam partes integrantes do processo educativo.

Diante disso, é válido salientar a importância que há no planejamento por parte do professor diante das aulas inovadoras para que dessa forma seu trabalho não seja pautado na imprevisibilidade, mas que seja algo consistente e sistemático. O professor de fato deve ter consciência da sua ação pedagógica, mas ao mesmo tempo é necessário que seja flexível e maleável, mediante os diferentes ritmos de aprendizagem dos alunos, como também acompanhando suas diversas necessidades, especificidades e capacidades.

Faz-se imprescindível que o momento da roda de conversação ocorra no contexto em sala de aula, partindo do pressuposto que este momento oportuniza a interação entre todas as crianças, favorecendo dessa forma a troca de ideias, experiências, diálogos, elaboração de conceitos, o desenvolvimento da linguagem oral e do pensamento. Nessa perspectiva, ainda é necessário elucidar acerca da presença do brincar em si, sendo que este elemento se consiste no ápice da ludicidade.

Desse modo, o educador deve estar ciente da importância da junção entre brincar e aprender, de forma que este trabalho pedagógico ocorra visando despertar o interesse, atenção, a motivação em si da criança desejar de fato aprender o que está sendo apresentado diante dela. 


\section{A MATEMÁTICA NA EDUCAÇÃO INFANTIL}

A educação infantil constitui-se como base imprescindível para o desenvolvimento de todos os eixos referentes ao processo de aprendizagem da criança. A exemplo da ampliação da coordenação motora, uma vez que, ela passa a desenvolver e aperfeiçoar seus movimentos, tanto pertinentes a motricidade grossa como a fina.

Pode-se mencionar também o aspecto da socialização/interação, na qual há uma troca de experiências em que decorre o conhecimento de si e do outro, por meio do diálogo, da comunicação mútua que o educador promove por intermédio das suas práticas pedagógicas. A exemplo do jogo, que se consiste como um elemento que oportuniza uma maior interação entre os envolvidos, tanto docentes quanto discentes.

Nessa perspectiva, não se pode deixar de mencionar a matemática como componente fundamental no processo de ensino aprendizagem e que está presente na vida da criança desde a sua infância. Comumente, percebe-se que a inserção da matemática na rotina de educação infantil, dá-se ainda de forma muito "mecânica", haja vista que muitos educadores fazem uso de métodos tradicionais para executar tal ação, a exemplo da denominada "decoreba" como forma de memorização da tabuada, em que os alunos não compreendiam o processo de resolução daquele dado problema e apenas memorizavam o resultado final para cada operação.

Vale ressaltar ainda, que nessa abordagem tradicional o docente não faz uso de atividades pautadas em materiais concretos, trazendo para os educandos suas respectivas realidades vivenciadas nos diferentes contextos existentes. Sendo assim, este acaba por mediar este processo de aprendizagem apenas por meio de abstrações, em que não há a representatividade por meio de algo palpável, dificultando assim na apreensão e compreensão do que está sendo apresentado. Nesse sentido,

A participação ativa da criança e a natureza lúdica e prazerosa inerentes a diferentes tipos de jogos têm servido de argumento para fortalecer essa concepção, segundo a qual aprende-se Matemática brincando. Isso em parte é correto, porque se contrapõe à orientação de que, para aprender Matemática, é necessário um ambiente em que predomine a rigidez, a disciplina e o silêncio (BRASIL, 1998, p. 211). 
O brincar, constitui-se como o principal elemento possibilitador da construção e desenvolvimento do conhecimento. É por intermédio da brincadeira, brinquedo e jogos que a criança conhece e percebe o mundo ao seu entorno, as pessoas, a sua cultura, dentre outros. Nesse sentido, vislumbra-se a importância de integrar o brincar no ensino da matemática, como uma forma de desenvolver uma motivação e interesse maiores em relação a esse componente.

Nessa perspectiva, pode-se mencionar o quão relevante os jogos educativos interdisciplinares se fazem na concretização do processo de ensino aprendizagem no percurso da educação infantil. Desse modo, pode-se considerar a ação pedagógica em si e os mecanismos para a sua execução.

Pode-se afirmar que estes elementos mencionados acima propiciam uma rica imaginação e criatividade, auxiliando na construção do sistema representativo da criança, haja vista que o brincar consiste na representação de símbolos - expressão da realidade -, beneficiando dessa forma a aquisição da leitura de mundo, que também é uma representação simbólica. Por esses fatores é que se faz tão necessário que o docente saiba introduzir o brincar na sua prática pedagógica e valorizá-lo como um recurso indispensável na educação infantil.

Nesse diapasão,

O jogo pode tornar-se uma estratégia didática quando as situações são planejadas e orientadas pelo adulto visando a uma finalidade de aprendizagem, isto é, proporcionar à criança algum tipo de conhecimento, alguma relação ou atitude. Para que isso ocorra, é necessário haver uma intencionalidade educativa, o que implica planejamento e previsão de etapas pelo professor, para alcançar objetivos predeterminados e extrair do jogo atividades que lhe são decorrentes (BRASIL, 1998, p. 211).

Ao trabalhar a matemática de forma lúdica e fazendo uso de materiais concretos, o educador deve ter clareza sobre quais são seus objetivos em relação às suas ações, havendo assim, estratégias, planejamentos e finalidades bem claras, a fim de que sua ação pedagógica possa ser pautada na reflexão e flexibilidade, levando em consideração os aspectos peculiares de cada sujeito.

A partir do momento em que se possibilita para a criança compartilhar suas vivências pessoais, ocorrerá um diálogo entre todos os envolvidos neste processo, o que amplificará as 
possibilidades de aprendizagem. Sendo que esta, decorrerá de forma muito mais significativa, principalmente com essa abertura a troca de experiências, ao ato de jogar, brincar e, sobretudo, divertir-se. Todos esses elementos favorecem a expansão do desenvolvimento, habilidades, capacidades e potencialidades dos educandos, uma vez que oportuniza que estes façam uso da imaginação para resolução de conflitos.

Mediante a leitura proposta do texto intitulado $A$ matemática no dia-a-dia da educação infantil, pode-se perceber qual a importância do brincar em roda, e da conversação sobre os conhecimentos de vida escolar do educando. Conforme a leitura realizada do referido texto, pode-se considerar que o momento da brincadeira em roda oportuniza a interação entre todas as crianças, uma vez que, possibilita a elaboração de conceitos, desenvolvimento do pensamento e da linguagem oral - estes constituem-se como elementos imprescindíveis no desenvolvimento da cognição da criança. Segundo Reame (2012, p. 19), "sentar em roda é um dos privilégios da Educação Infantil, constituindo-se em um espaço que favorece um autoconhecimento, o conhecimento do outro e das relações entre esses e o mundo que os rodeia".

É válido salientar também que este momento oportuniza a criança momentos lúdicos, considerando que se utiliza do brincar como elemento primordial na construção e desenvolvimento da aprendizagem infantil. Este momento tão recorrente no âmbito educacional, também propicia o desenvolvimento da autonomia, da autoexpressão, criatividade, imaginação e consequentemente o autoconhecimento. Com o desenvolvimento desses aspectos mencionados, torna-se viável a amplificação do arsenal vocabulário da criança. É possível ainda que o professor explique os pontos a serem desenvolvidos naquele dado momento.

Ao trabalhar-se a matemática neste nível de ensino, é necessário que o educador planeje e trace objetivos bem claros a fim de desenvolver a partir de conteúdos matemáticos integrados a roda de conversa, práticas pedagógicas inovadoras que oportunizem a ampliação do pensamento e da linguagem oral acerca dos conceitos primários de matemática, favorecendo a socialização entre as crianças na sala de educação infantil, com o intuito de desenvolver o autoconhecimento da criança e a percepção do outro, utilizando-se da sequência numérica para tal e desse modo, viabilizando uma maior interação entre as crianças e o educador da educação infantil. 
A interação social em situações diversas é uma das estratégias mais importantes do professor para a promoção de aprendizagens pelas crianças. Assim cabe ao professor propiciar situações de conversa, brincadeiras ou de aprendizagens orientadas que garantam a troca entre as crianças, de forma a que possam comunicar-se e expressar-se, demonstrando seus modos de agir, de pensar e de sentir, em um ambiente acolhedor e que propicie a confiança e a autoestima (BRASIL, 1998, p. 31).

Observa-se que este aspecto é de suma importância para o aperfeiçoamento das experiências vivenciadas pela criança em sua trajetória escolar, principalmente na educação infantil. Nota-se aqui, o quão fundamental se torna a postura do docente acerca deste elemento, que quando bem trabalhado e conduzido ocasionará relevantes evoluções na (s) criança (s).

\section{A MATEMÁTICA NOS ANOS INICIAIS DO ENSINO FUNDAMENTAL}

Ao que se refere à mediação do professor decorrente nos anos iniciais do ensino fundamental, pode-se mencionar que os jogos educativos se constituem ainda, como instrumentos facilitadores do processo de ensino aprendizagem, haja vista que, o próprio aluno seria o construtor do seu conhecimento pela elaboração de tais recursos metodológicos. Ou seja, a partir do momento que o educador dá aos educandos a possibilidade de criar tais estratégias de ensino, a exemplo dos jogos educativos, ocorre assim uma maior facilidade ao que se refere a apreensão e aquisição dos conhecimentos matemáticos.

No transcorrer do processo educativo da criança, mais especificamente os níveis que compreendem os anos iniciais do ensino fundamental, vale frisar a importância de se trabalhar as quatro operações de forma prazerosa e dinâmica, pautadas na ludicidade. Acontecendo dessa forma, uma aprendizagem satisfatória e significativa para o educando em pleno processo formativo.

O mais importante no ensino de conceitos básicos é ajudar a criança a passar progressivamente do pensamento concreto à utilização de modos de pensamento conceptualmente mais adequados. É ocioso, porém, tentar fazêlo pela apresentação de explicações formais, baseadas numa lógica muito distante da maneira de pensar da criança e, para ela, estéril em suas implicações (BRUNER, 1978, p. 36). 
A adição é de substancial importância para o processo de ensino aprendizagem, tendo em vista que esta é a operação que embasa a aquisição e compreensão das demais operações. A partir da adição a criança terá o primeiro contato com o ensino da matemática mais sistematizado. Sendo importante destacar que a criança já traz consigo conhecimentos provenientes do seu contexto de vivência para a sala de aula, porém ela ainda não tem a compreensão do conceito de adição. É justamente na escola que esses conhecimentos serão sistematizados.

Trabalhar com a adição é bastante relevante, principalmente quando isso é feito de maneira adequada. É importante que o educador traga para sala de aula exemplos concretos, situações problemas que exijam do aluno o desenvolvimento de um raciocínio mais complexo, que incentive o cálculo com as mãos. Apesar de ser um método criticado para um adulto, para quem está começando e se familiarizar com os números, é muito interessante, pois facilita a assimilação do conhecimento dos números.

É importante elucidar também que a subtração é o mesmo que a adição por um número de sinal inverso. É, portanto, a operação inversa da adição. A subtração é a operação de subtrair (separar uma parte de um todo, tirar, perder, eliminar, baixar, reduzir ou cortar algo).

Trata-se de uma das quatro operações básicas da matemática e a mais simples bem como a adição - ou soma. Ambas são "faces de uma mesma moeda", pois para a compreensão da subtração faz-se necessário o entendimento do conceito de adição. A subtração é uma operação de decomposição: a uma certa quantidade, é eliminada uma parte dela e obtém-se um resultado - chamado diferença.

A operação cujo nome é multiplicação é pela ordem a terceira a ser trabalhada e o educando já traz consigo conhecimentos acerca dos números, uma vez que, estes já foram trabalhados na adição e subtração.

Essa operação, faz-se importante pelo fato de oportunizar ao educando o desenvolvimento de conceitos matemáticos, bem como a amplificação da capacidade de realizar cálculos mentais e solucionar problemas advindos do cotidiano tais como: realização de compras no supermercado, comprar pães na padaria, dividir um doce com um amigo, na cozinha fazendo uma receita, para saber a altura que conseguirmos pular, entre outros, por meio de suas próprias estratégias - planejar, raciocinar e solucionar. 
Ela objetiva oportunizar ao educando a apropriação dos saberes matemáticos, especificamente a conceituação e compreensão da multiplicação para que nos anos posteriores a aprendizagem ocorra de forma mais acessível e compreensível.

Para que este processo seja viável e decorra de forma produtiva, faz-se preciso que o educador busque trabalhar a princípio as questões referentes ao surgimento da multiplicação, bem como aplicar situações problema advindas do contexto que a criança está inserida, de forma a facilitar a internalização do conceito de multiplicação.

Por fim a divisão é uma operação semelhante à subtração, uma vez que, consiste no fato de partilhar algo - o objeto. Esta é a última das operações a ser trabalhada no âmbito escolar, sendo importante elucidar que a criança, desde a educação infantil, já possui o contato com a divisão nas suas mais diversas experiências cotidianas. Contudo, esta ainda não compreende o conceito de divisão em uma perspectiva teórica sistemática.

Nesse sentido, as maiores dificuldades surgem no momento em que essas situações operacionais são apresentadas de forma não contextualizada com a realidade experienciada pelo educando. Emerge então, a importância de o educador desenvolver um trabalho pedagógico respaldado exatamente nesse contexto vivenciado pelo aluno.

É importante que o educador apresente situações por meio de objetos concretos para a interiorização do que é a divisão. O professor diante desse processo de ensino aprendizagem, poderá trabalhar de forma a evitar o egocentrismo, aspecto esse tão recorrente no contexto escolar, bem como agir no sentido de desenvolver a percepção e o reconhecimento da importância de se dividir, principalmente, no que se refere a socialização e compartilhamento dos materiais escolares disponíveis em sala de aula.

\section{CONSIDERAÇÕES FINAIS}

Pela consideração dos aspectos analisados na disciplina Fundamentos e Metodologia do Ensino da Matemática, pode-se perceber a importância que esta tem para o processo formativo, tanto para os discentes enquanto sujeitos em processo de formação pessoal e acadêmica, quanto para a apreensão de estratégias de mediação na ação pedagógica.

O referido trabalho oportunizou uma amplificação dos nossos conhecimentos pertinentes ao ensino da matemática, bem como uma visão diferenciada sobre ela, haja vista que, houve uma desmistificação da percepção que tínhamos acerca desta área do 
conhecimento, em que a ela por ser trabalhada de forma tradicional, apenas por meio da denominada "decoreba", acaba por diversas vezes inibindo e limitando o educando para o interesse de apreender tais conteúdos.

Nessa perspectiva, considera-se que a partir destes estudos se tornou viável o entendimento da matemática pautada em uma abordagem lúdica, onde por meio de estratégias e intervenções baseadas na dinâmica, é possível realizar um trabalho pedagógico de qualidade, uma vez que, este possibilita uma aprendizagem mais consistente, satisfatória e qualitativa, levando em consideração que o educando terá um maior interesse mediante o que está sendo apresentado em sala de aula.

Diante do exposto acima, é válido salientar que tanto nos âmbitos referentes a educação infantil quanto nos anos iniciais do ensino fundamental, é essencial que o educador busque formas lúdicas para desempenhar sua ação pedagógica, a exemplo dos jogos educativos que possibilitam a apreensão dos conceitos matemáticos, uma vez que são trabalhados a partir da utilização de materiais concretos, ocorrendo assim uma maior internalização das noções numéricas.

Logo, o ensino da matemática consiste-se como um instrumento imprescindível para a construção e desenvolvimento do processo educativo e cognitivo do sujeito, uma vez que, esta se faz presente em todos os âmbitos, tanto pessoal, social, cultural, quanto no desempenho acadêmico e profissional do indivíduo.

\section{REFERÊNCIAS BIBLIOGRÁFICAS:}

BRASIL. Ministério da educação e do Desporto. Secretaria de Educação Fundamental Referenciais curriculares nacionais para a educação infantil / Ministério da Educação e do Desporto, Secretaria de Educação Fundamental. - Brasília: MEC/SEF, 1998. Disponível em: http://portal.mec.gov.br/seb/arquivos/pdf/renei_vol 1. pdf. Acesso em: 05 de julho de $\underline{2017}$

BRUNER, J.S. O processo da educação. São Paulo: Nacional, 1978.

CANAL, D. C. et al. O Ensino da Matemática Nos Anos Iniciais Numa Perspectiva Ludopedagógica. Canoas: ULBRA, 2013.

GRANDO, Regina Célia. O jogo e a matemática no contexto da sala de aula. São Paulo: Paulus, 2004. 
MOURA, Manoel Oriosvaldo. O Jogo e a Construção do Conhecimento Matemático. São Paulo: Publicação séries e ideias, 1992.

OLIVEIRA, Sandra Alves de. O lúdico no ensino da matemática: re-significando a prática pedagógica. Disponível em:

http://www.enrede.ufscar.br/participantes_arquivos/E6_OLIVEIRA_RE.doc._1_.pdf Acesso em: 06 de julho de 2017.

REAME.E [et al.]. Matemática no dia a dia da educação infantil: rodas, cantos, brincadeiras e histórias. São Paulo: Livraria Saraiva, 2012. 